\title{
DEVELOPMENT OF THE INFLOW PREDICTION MODEL ON TROPICAL RESERVOIR USING ADAPTIVE NEURO FUZZY INFERENCE SYSTEM
}

\author{
Imam Suprayogi \\ Civil Engineering Department, Faculty of Engineering, \\ Riau University, Pekanbaru, Indonesia
}

Alfian

Civil Engineering Department, Faculty of Engineering, Riau University, Pekanbaru, Indonesia

Joleha

Civil Engineering Department, Faculty of Engineering, Riau University, Pekanbaru, Indonesia

Nurdin

Civil Engineering Department, Faculty of Engineering, Riau University, Pekanbaru, Indonesia

\section{Bochari}

Civil Engineering Department, Faculty of Engineering, Riau University, Pekanbaru, Indonesia

Azmeri

Civil Engineering Department, Faculty of Engineering, SyiahKuala University, Banda Aceh, Indonesia

\begin{abstract}
Inflow prediction is a key in component planning, design, operation, development, and maintenance of availiable water resources. The inflow prediction model have many benefits in the application of Water Resources such as flood control, preventing drought, and optimizing reservoir operation for hydropower system sustainability. The main purpose of the research is to develop of model to predict the inflow of hydro electric power plant reservoir considering the importance of information on sufficient in this reservoir everyday so that the hydro electric power plant can continue to operate. The method of research approach used is using Adaptive Neuro Fuzzy Inferences System developed a hybrid system between fuzzy logic and artificial neural network as branch of softcomputing. The location of research on the Kotopanjang hydro electric power plant reservoir in Merangin Village, Kampar Residence, Riau Province. The data used in this research is secondary data in the form of inflow data
\end{abstract}


Development of the Inflow Prediction Model on Tropical Reservoir Using Adaptive Neuro Fuzzy Inference System

of Kotopanjang hydro electric power plant reservoir which has been done by PT PLN (Persero) KIT Sumbagut Sektor, KIT Pekanbaru from 2007-2012. The main results of the research proved that the implementation of a inflow prediction model on the tropical reservoir in Kampar Residence using the ANFIS method with cross validation approach for the next annual $(Q t+1)$ has a very strong classification tested using statistical parameters coefficient of correlation $(R)$ and mean absolute percentage error (MAPE) respectively value of 0.94 and $12.86 \%$

Keywords: Model, prediction, inflow, tropical reservoir, Adaptive Neuro Fuzzy Inference System.

Cite this Article: Imam Suprayogi, Alfian, Joleha, Nurdin, Bochari and Azmeri, Development of the Inflow Prediction Model on Tropical Reservoir Using Adaptive Neuro Fuzzy Inference System. International Journal of Civil Engineering and Technology, 11(4), 2020, pp. 171-183.

https://iaeme.com/Home/issue/IJCIET?Volume=11\&Issue=4

\section{INTRODUCTION}

Inflow prediction is a key in component planning, design, operation, development, and maintenance of availiable water resources. The inflow prediction model have many benefits in the application of Water Resources such as flood control, preventing drought, and optimizing reservoir operation for hydropower system sustainability. Inflow prediction models have many benefits in natural resources aplication, such as flood control, preventing drought, and optimizing reservoir operation for the sustainability of hydro electric systems (Magar, 2012). Inflow data errors can cause uncertainty in predicting reservoir sedimentation. Further in planning, data series inflow reservoirs are required as inputs on modeling of reservoir operations and reservoir sedimentation, so the accuracy of the data is indispensable. The model results will be biased if an input data error occurs (Salas and Shin, 1999).

Accurate time and site specific forecasts of stream flows and reservoir inflow are required for effective hydro power reservoir management and scheduling. In the past few decades, a wide range of hydrologic models has been proposed for this purpose. In Indonesia, there are five methods of flow forecasting used by default i.e. simple forecasting method, forecasting method of correlation and regression, recession forecasting method, and time series analysis method using Auto Regression (AR) method and Stochastic method Thomas-Fiering (Department of Housing and Regional Infrastructure, 2003). Conventionally, factor analysis and hydrological analysis methods such as historical evolution method, time series analysis, multiple linear regression method and so forth, are used to forecast the long term discharges. Nowadays, time series analysis and multiple linear regression method are the two most commonly used methods. The time series analysisis based on the decomposition of various factors into trend and cycle. After 1970s, Autoregressive Moving Average (ARMA) models proposed by Box et al. (1976) are also widely used. The weakness of such conventional methods is the quality of forecasting and the needs of many other additional parameters such as the physical nature of the catchment area, and the river network (Firat and Gungor, 2007).

Since 1990s, artificial neural network (ANN), based on the understanding of the brain and nervous systems, is gradually used in hydrological prediction, such as : rainfall forecasting (Sajikumar and Thandaveswara, 1999), (Bodri and Čermák, 2000); (Luk, et al., 2001)); stream flow forecasting (Kim and Barros, 2001); Campolo, et al., 2003; Hu, et al., 2005); groundwater level prediction (Giustolisi and Simeone,2006; Suprayogi, et al., 2020); modeling the infiltration process (Sy, 2006); reservoir operations (Hasebe and Nagayama, 
2002; Chang,et al., 2005; Kim, et al., 2009 ); rainfall-runoff modelling (Wilby, et al., 2003; Giustolisi and Laucelli, 2005); parameter estimation of hydrological models (Rowinski, et al., 2005); uncertainty analysis of hydrological model parameters (Ozelkan and Duckstein, 2004); and modelling of time series (Sisman-Yilmanz, et al., 2004; Nayak, et al., 2004a).

The Fuzzy rule-based approach introduced by Zadeh (1965) is being widely utilized in various fields of science and technology. It is a qualitative modeling scheme in which the system behaviouris described using a natural language. The transparency in formulation of fuzzy rules offers explicit qualitative and quantitative insights into the physical behavior of the system (Copolla, et al., 2000).The application of fuzzy logic as a modeling tool in the field of water resources is a relatively new concept although some studies have been carried out to some extent in the last decade and these have generated much enthusiasm. Bardossy and Duckstein (1992) applied a fuzzy rule-based modeling approach to a karstic aquifer management problem. Fontane, et al., (1997) and Panigrahi and Mujumdar (2000) applied fuzzy logic for reservoir operation and management problems. Bardossy and Disse (1993) used fuzzy rules for simulating infiltration. Bisht, et al., (2009) used fuzzy rules for simulation of water table elevation fluctuation. Lohani, et al., (2006) used Takagi-Sugeno fuzzy inference system for modeling stage-discharge relationship.

\subsection{Importance of Inflow Prediction on Tropical Reservoir}

Reservoirs in wet tropical areas generally have a fairly rapid sedimentation problem. There is rarely an operating reservoir indicating an increased sedimentation phenomenon. Based on several reports and research, many reservoirs are experiencing faster than the original age. Among others, it is noted on the Wonogiri, Sutami, Saguling, Wlingi dams in Indonesia, Bahkara in India, Magat in Philliphines and Kamburu in Kenya an increase in sediment rate of two or three times from its initial design after remonitoring (Sudjarwadi, 1995; Ilyas, 1995).

The Kotopanjang reservoir is a single purpose reservoir as a hydro electric power plant that utilize the water potential of Kampar Kanan river. The mentioned Kampar Kanan river channel is dammed to collect and raise the water level to obtain the planned water level and the amount of discharge that can be taken throughout the year required to rotate the Kotopanjang hydro electric power plant turbine. The Kotopanjang hydro electric power plant water discharge condition that continue to decline forced PLN to extinguish some customers in rotation since the end of May to August. From the total electricity needed for the Riau land area of $20 \mathrm{MW}$, the Kotopanjang hydro electric power plant was only able to produce electricity of $60 \mathrm{MW}$ from its maximum capacity of $114 \mathrm{MW}$ (Akbari, 2012). The character of rain in northern part of Sumatra divided into two, which is located on the East of Bukit Barisan and West of Bukit Barisan. The rainfall in the east of Bukit Barisan has the characteristics of rainfall which is lower than the average of the entire region of North Sumatra. And the rainfall in the west of Bukit Barisan has the characteristics of rainfall which is higher than the average of the entire region of Northern Sumatra (Akbari, 2012).

The most important issue in the management of the Kotopanjang hydro electric power plant reservoir is the amount of inflow discharge as it determines the amount of water to be dicharged to power the turbine generator. Mid June 2006 PT.PLN conducted weather modification technique (TMC) through artificial rain to increase the water discharge due to low water discharge in Kotopanjang hydro electric power plant and at that time the alleged water level in Kotopanjang hydro electric power plant reach 73.8 mdpl impact turbine of power plant can not produce electric power, which can only produce when the water surface reaches $76.4 \mathrm{~m} \mathrm{dpl}$. 
Development of the Inflow Prediction Model on Tropical Reservoir Using Adaptive Neuro Fuzzy Inference System

\subsection{Implementation Model ANFIS}

Sometimes the main components of softcomputing match each other in order to get a more perfect algorithm. In 1993, Roger Jang from the Electrical and Computer Science Department, University of California, USA.developed a hybrid system between fuzzy logic and artificial neural network that produced a neuro fuzzy system of adaptive neuro fuzzy inference system structure or better known as ANFIS algorithm. A fuzzy-logic approach and neural networks have been applied to a variety of hydrological problems, such as stream flow forecasting (Chang and Chen, 2001; Ponnambalan, et al., 2003; Vernieuwe, et al., 2005), modelling of time series (Sisman-Yilmanz, et al., 2004; Nayak, et al., 2004b), reservoir water level prediction (Chang and Chang, 2006), reservoir operations (Ouenes, 2000), evaluated to improve the accuracy of river flow forecasting (Kisi, 2004; Firat, 2007).

Lin, et al., (2005) has successfully developed the ANFIS model to forecast long term discharges of Manwan hydro electric power plant. Manwan hydro electric power plant uses Lancangjiang river that originates from the Qinghai Plateu and ends in the South China Sea as its water resources. Lin's research shows that ANFIS model gives good prediction performance with correlation between the prediction value and the observation value are 0.89 and 0.92 respectively. The adoption of different membership functions for ANFIS show that the TRAPMF performs the best in long-term prediction of discharges in Manwan Hydro power consisting of three antecedent flows in input.Itis found,through result comparison with an appropriate ANN model, that the ANFIS model is able to give more accurate prediction. This demonstrates its distinct capability and advantages in identifying hydrological time series comprising non-linear characteristics. Referring to the success of research using ANFIS as a reservoir inflow forecasting model, it is necessary to test the reliability of the ANFIS model to predict the inflow of Kotopanjang hydro electric power plant reservoir considering the importance of information on sufficient in this reservoir everyday so that the Kotopanjang hydro electric power plant can continue to operate.

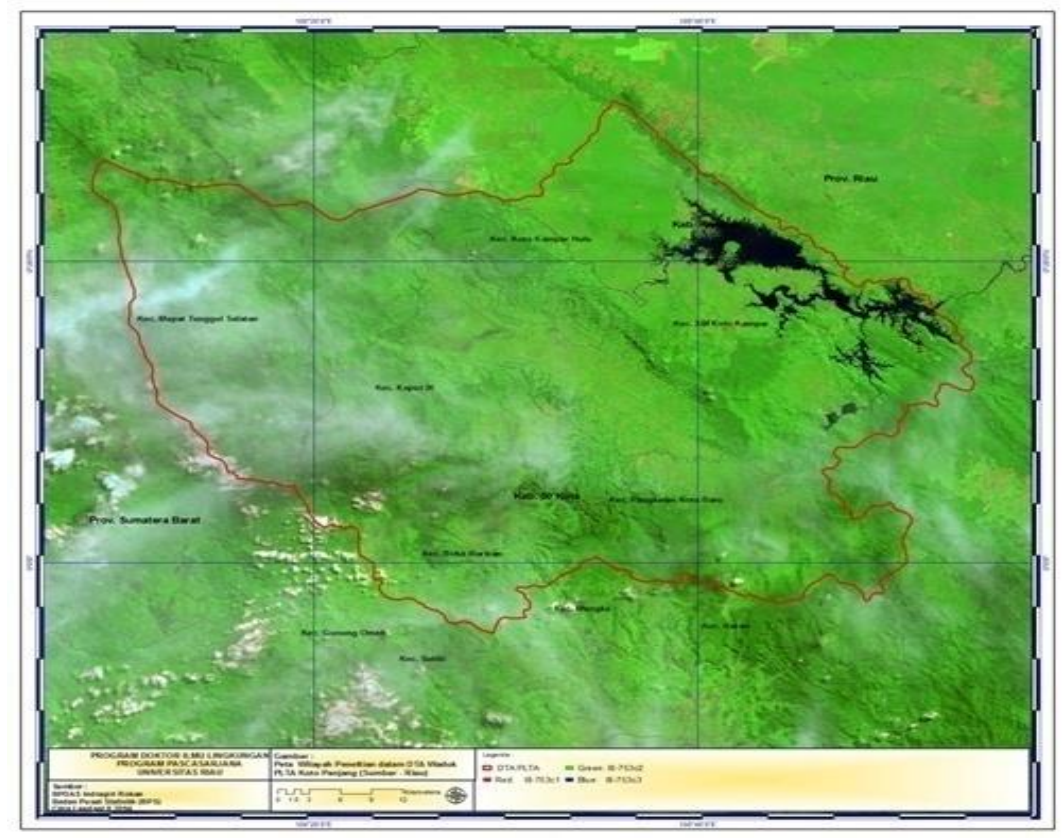

Figure 1 Location of Kotopanjang hydro electrical powerplant on tropical reservoir points 


\section{DATA USED AND INFLOW PREDICTION MODELING}

The data used in this research is secondary data in the form of inflow data of Kotopanjang hydro electric power plant reservoir which has been done by PT PLN (Persero) KIT Sumbagut Sektor, KIT Pekanbaru from 2007-2012. The stage analysis of inflow prediction on tropical reservoir using the ANFIS method approach is presented as shown in Figure 2 below:

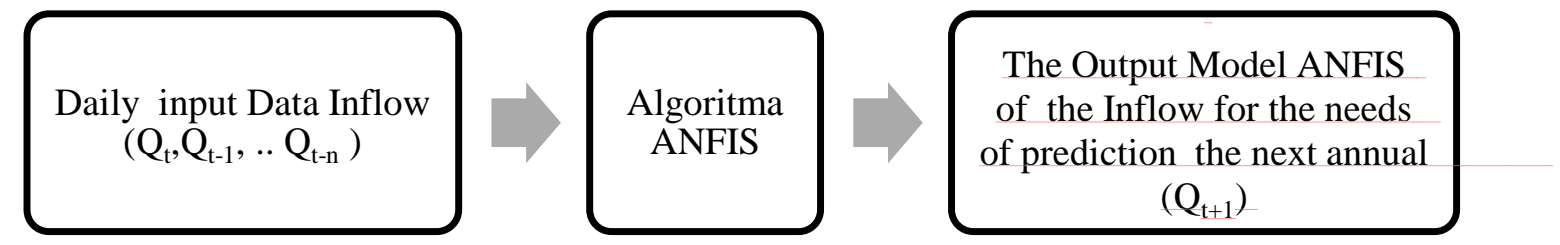

Figure 2 Stages of analysis inflow prediction using the method ANFIS

Step solution inflow prediction model on tropical reservoir using ANFIS algorithm

- The preparation of data from the form of inflow data of Kotopanjang hydro electric power plant reservoir which has been done by PT PLN (Persero) KIT Sumbagut Sektor, KIT Pekanbaru from 2007-2012,

- Model development stage, 70\% of total inflow data year 2007-2010 is used as training data and $30 \%$ is used as test data. Then all the data of 2007-2010 is used as simulation data to see the results of the data training and testing process of the overall model development stage.

- The 2007-2010 data is also used as validation data, which the model rules will be applied to build ANFIS model using the data of 2011. Data of 2012 is the data that will be used for the reservoir inflow prediction needs for one annual ahead using ANFIS rule model.

- The final process with the prediction process of inflow on reservoir after ANFIS model is done after a series of training process, testing and simulation of finished model. The prediction result of the ANFIS model (output) is then compared to the measurement result value. ANFIS model conformance and measurement results using statistical parameter test mean average percentage error (MAPE), root mean square error (RMSE) and coefficient of correlation (R) to get the best correlation rate result at prediction process

The performance of each model was studied under the statistical performance criteria of the coefficient of correlation (R), the root mean square error (RMSE), and the mean absolute percentage error (MAPE). The values of each model were compared with observed discharge ( $\left.Q_{\text {obs}}\right)$. The precision evaluation of the model is conducted by comparing the inflow of the model ANFIS simulation and the data of the available measurement results. Models can be said to be precise if there is a high correlation value between simulated and measured result data. One of the statistical parameter tests is the correlation coefficient $(\mathrm{R})$ is the value indicating the magnitude of the relation between the value of observation and the simulation value. The model precision test is done using the correlation coefficient $(\mathrm{R})$ which follows the equation as follows:

$$
R=\frac{\sum_{i=1}^{i=N} Q_{p} Q_{m}}{\left[\sum_{i=1}^{i=N} \Delta Q_{p}{ }^{2} \sum_{i=1}^{i=N} \Delta Q_{m}{ }^{2}\right]^{1 / 2}}
$$




$$
\Delta \mathrm{Q}_{\mathrm{p}}=\mathrm{Q}_{\mathrm{pi}}-\bar{Q}_{\mathrm{p}} \text { and } \Delta \mathrm{Q}_{\mathrm{mi}}=\mathrm{Q}_{\mathrm{mi}}-\bar{Q}_{m i}
$$

Where $\mathrm{Q}_{\mathrm{p}}$ as the discharge observed $\left(\mathrm{m}^{3} / \mathrm{s}\right), \mathrm{Q}_{\mathrm{m}}$ is the discharge model $\left(\mathrm{m}^{3} / \mathrm{s}\right)$, and $\mathrm{n}$ is the number of samples.

Classification of the strength of degree of relationship based on result coefficient value correlation between simulation result of model and measurement result data. For $\mathrm{R}$ equals 0 has a relationship degree no correlation, $0<\mathrm{R}<0.25$ has a very weak degree of correlation relationship, $0.25<\mathrm{R}<0.50$ has a degree of insufficient correlation relationship, $0.50<\mathrm{R}<$ 0.75 has a strong correlation degree, $0.75<\mathrm{R}<0.99$ degrees correlation relationship is very strong and R equals 1 degree of perfect correlation relationship (De Farias et al, 2010; Firat, 2007).

The root-mean square error (RMSE) represents the square root of the second sample moment of the differences between predicted values and observed values or the quadratic mean of these differences. RMSE is a measure of accuracy, to compare forecasting errors of different models for a particular data set and not between data sets, as it is scale-dependent. RMSE is the level of error prediction results, when the smaller (closer to 0) of RMSE value then the prediction result will be more accurate. The RMSE value can be calculated with below equation (Firat, 2007):

$$
R M S E=\left[\frac{1}{N} \sum_{i}^{N}\left(Q_{\text {observed }}-Q_{\text {predicted }}\right)\right]^{\frac{1}{2}}
$$

With Q Qbserved is actual discharge $\left(\mathrm{m}^{3} / \mathrm{s}\right)$, Qmodel is predicted discharge $\left(\mathrm{m}^{3} / \mathrm{s}\right)$ dan $\mathrm{n}$ is sum data discharge and $\mathrm{n}$ is number of data

The mean absolute percentage error (MAPE), also known as mean absolute percentage deviation (MAPD), is a measure of prediction accuracy of a forecasting method in statistics, for example in trend estimation, also used as a loss function for regression problems in machine learning. It usually expresses the accuracy as a ratio defined by the formula (Nayak, et al, 2004a):

$$
M A P E=\frac{\sum a b s\left(\frac{Q_{\text {observed }}-Q_{\text {predicted }}}{Q_{\text {observed }}}\right)}{n} \times 100 \%
$$

with Qobserved is observed discharge $\left(\mathrm{m}^{3} / \mathrm{s}\right)$, Qpredicted is predicted discharge $\left(\mathrm{m}^{3} / \mathrm{s}\right)$ dan $\mathrm{n}$ is number of data discharge. Note that the MAPE is also sometimes reported as a percentage, which is the above equation multiplied by 100 .

\section{RESULTS AND DISCUSSION}

\subsection{ANFIS Model Development}

The design of neuro fuzzy system network architecture with ANFIS structure used the pattern of input-output taken from inflow data of Kotopanjang hydro electric power plant reservoir from 2007 until 2010. The relationship pattern between input and output inflow data used to build the ANFIS model is then compiled in time series with mathematical formula as presented in equation below:

$$
\begin{aligned}
& Q_{t+1=} f\left(Q_{t}\right) \\
& Q_{t+1}=f\left(Q_{t-1}, Q_{t}\right) \\
& Q_{t+1=} f\left(Q_{t-2}, Q_{t-1}, Q_{t}\right) \\
& Q_{t+1}=f\left(Q_{t-3}, Q_{t-2}, Q_{t-1}, Q_{t}\right)
\end{aligned}
$$


where $\mathrm{Q}_{\mathrm{t}}$ is the inflow at $\mathrm{t}\left(\mathrm{m}^{3} / \mathrm{s}\right), \mathrm{Q}_{\mathrm{t}-1}$ is inflow at $\mathrm{t}-1\left(\mathrm{~m}^{3} / \mathrm{s}\right), \mathrm{Q}_{\mathrm{t}-2}$ is inflow at $\mathrm{t}-2\left(\mathrm{~m}^{3} / \mathrm{s}\right), \mathrm{Q}_{\mathrm{t}-3}$ is inflow at $\mathrm{t}-3\left(\mathrm{~m}^{3} / \mathrm{s}\right)$ and $\mathrm{Q}_{\mathrm{t}+1}$ is the inflow at $\mathrm{t}+1\left(\mathrm{~m}^{3} / \mathrm{s}\right)$.

Furthermore, the model scheme for the various variations of the input quantities tested to build the ANFIS model in this study is presented as in the Table 1 below:

Table 1 The ANFIS Model Scheme

\begin{tabular}{ccc}
\hline Scheme Model & Input Model & Output Model \\
\hline 1 & $\mathrm{Q}_{\mathrm{t}}$ & $\mathrm{Q}_{\mathrm{t}+1}$ \\
2 & $\mathrm{Q}_{\mathrm{t}}, \mathrm{Q}_{\mathrm{t}-1}$ & $\mathrm{Q}_{\mathrm{t}+1}$ \\
3 & $\mathrm{Q}_{\mathrm{t}}, \mathrm{Q}_{\mathrm{t}-1}, \mathrm{Q}_{\mathrm{t}-2}$ & $\mathrm{Q}_{\mathrm{t}+1}$ \\
4 & $\mathrm{Q}_{\mathrm{t}}, \mathrm{Q}_{\mathrm{t}-1}, \mathrm{Q}_{\mathrm{t}-2,}, \mathrm{Q}_{\mathrm{t}-3}$ & $\mathrm{Q}_{\mathrm{t}+1}$ \\
\hline
\end{tabular}

There are two very important stages in the prediction process using the ANFIS algorithm that is the process of training data and the testing process data (Suprayogi, 2009). Applications with the ANFIS structure require data training and data testing. Both contain an input/output pattern. If training data was used to train the structure of ANFIS, data testing was used to assess the performance of the ANFIS structure. There are three stages in building a high forecasting model from inflow data of Kotopanjang hydro electric power plant reservoir from 2007 until 2010 using the ANFIS algorithm which is stages of training process, testing process, and model validation process.

\subsection{Training Model}

The process of training model is used to train the structure of ANFIS. In the stage of training model using the method ANFIS algorithm first done test process statistical parameters coefficient correlation (R) and root mean square error (RMSE) to get the best R and RMSE value from the one model ANFIS parameter is range of influence (ROI). Data training is used to train the ANFIS structure is 70\% from 1 January 2007 until 20 Sept 2009 of the inflow data of Kotopanjang hydro electric power plant reservoir which has been done by PT PLN (Persero) KIT Sumbagut Sektor, KIT Pekanbaru, Kotopanjang hydro electric power plant unit. The complete result of data training process at various scheme using MATLAB 7.0 auxilary program is presented as Table 2 below:

Table 2 Best parameter value of Model ANFIS at Phase Training Process

\begin{tabular}{cccccc}
\hline Scheme & Input & Output & $\begin{array}{c}\text { Range of } \\
\text { Influence (ROI) }\end{array}$ & R & RMSE \\
\hline 1 & $\mathrm{Q}_{\mathrm{t}}$ & $\mathrm{Q}_{\mathrm{t}+1}$ & 0.00005 & 0.908 & 2.89 \\
2 & $\mathrm{Q}_{\mathrm{t}}, \mathrm{Q}_{\mathrm{t}-1}$ & $\mathrm{Q}_{\mathrm{t}+1}$ & 0.0004 & 0.913 & 0.000118 \\
3 & $\mathrm{Q}_{\mathrm{t}}, \mathrm{Q}_{\mathrm{t}-1}, \mathrm{Q}_{\mathrm{t}-2}$ & $\mathrm{Q}_{\mathrm{t}+1}$ & 0.080 & 0.937 & 0.000006 \\
4 & $\mathrm{Q}_{\mathrm{t}}, \mathrm{Q}_{\mathrm{t}-1}, \mathrm{Q}_{\mathrm{t}-2,}, \mathrm{Q}_{\mathrm{t}-3}$ & $\mathrm{Q}_{\mathrm{t}+1}$ & 0.09 & 0.924 & 0.000008 \\
\hline
\end{tabular}

Source: MATLAB program running result

Referring from Table 2 above, it will be obtained statistical parameter test value in data training process between ANFIS model (best scheme 3) and observation data in field has very strong classification with correlation coefficient (R) and RMSE value respectively 0.937 and 0.000006 with ROI parameter value 0.08 .

\subsection{Testing Model}

After the process of training data that aims to train the structure of ANFIS then the next step is done the process of testing data using the architecture of ANFIS model consisting of three input layer and one output, which is used to assess the performance of the ANFIS structure. 
Development of the Inflow Prediction Model on Tropical Reservoir Using Adaptive Neuro Fuzzy Inference System

Results of data testing analysis with datainput 21 September 2009 until 31 December 2010 (30\% data other than the data used traning process). The full results of the data testing process using the MATLAB 7.0 aids program are more fully presented as Table 3 below.

Table 3 Performance of Model ANFIS at Phase Testing Process

\begin{tabular}{cccccc}
\hline Scheme & Input & Output & R & RMSE & Classification \\
\hline 3 & $\mathrm{Q}_{\mathrm{t}}, \mathrm{Q}_{\mathrm{t}-1, \mathrm{Q}_{\mathrm{t}-2}}$ & $\mathrm{Q}_{\mathrm{t}+1}$ & 0.57 & 154.81 & Strong \\
\hline
\end{tabular}

Source : MATLAB program running result

Referring from Table 3 above, it will be obtained statistical parameter test value in data testing process between ANFIS model and observation data in field has strong classification with correlation coefficient (R) and RMSE value respectively 0.57 and 154.81 .

\subsection{Simulation Model}

The model simulation according to Refsgaard (2000) is an attempt to simulate the use of the model to obtain predicts that the water resource management can use. Model simulation stage is the last process after the training process and the testing phase. Results of the analysis of data simulation with data input 1 January 2007 until 31 December 2010 using the MATLAB 7.0 aids program are more fully presented as Table 4 below.

Table 4 Performance of Model ANFIS at Phase Simulation Process

\begin{tabular}{cccccc}
\hline Scheme & Input & Output & R & RMSE & Correlation \\
\hline 3 & $\mathrm{Q}_{\mathrm{t}}, \mathrm{Q}_{\mathrm{t}-1}, \mathrm{Q}_{\mathrm{t}-2}$ & $\mathrm{Q}_{\mathrm{t}+1}$ & 0.85 & 90.31 & Very Strong \\
\hline
\end{tabular}

Source : MATLAB program running result

Referring from Table 4 above, it will be obtained statistical parameter test value in data simulation process between ANFIS model and observation data in field has strong classification with correlation coefficient (R) and RMSE value respectively 0.85 and 90.31 .

\subsection{Prediction of Inflow in reservoir using ANFIS Model}

There are two model schemes to do the prediction of the inflow of Kotopanjang hydro electric reservoir for the year 2012 using the ANFIS method approach based on the discharge data information in the year 2011 sourced from by PT PLN (Persero) KIT Sumbagut Sektor, KIT Pekanbaru by implementing scheme 1 without cross validation and scheme 2 with cross validation. The main purpose of the use of cross validation method is to test the quality of data used for forecasting by performing the composition of training and testing process on ANFIS input data without using cross validation. If the cross validation process gives better prediction results then the data used for the prediction of inflow of the hydro electrical reservoir is considered to have a better forecasting quality when compared to an ANFIS model without cross simulation. For the composition of the data training, data testing and simulation data for the prediction of inflow Kotopanjang hydro electric reservoir for the year 2012 presented as in Table 5 below 
Imam Suprayogi, Alfian, Joleha, Nurdin, Bochari and Azmeri

Table 5 Composition Training, Testing and Simulation Data

\begin{tabular}{|c|c|c|c|}
\hline Scheme & Input Training Data & Input Testing Data & Input Simulation Data \\
\hline Scheme 1 & $\begin{array}{c}\text { 256 data (70\%) } \\
\text { 1 Jan-13 Sept 2011 }\end{array}$ & $\begin{array}{c}\text { 109 data (30\%) } \\
\text { 14 Sept -21 Dec 2011 }\end{array}$ & $\begin{array}{c}\text { 365 data (100\%) } \\
\text { 1 Jan-31 Dec 2011 }\end{array}$ \\
\hline Scheme 2 & $\begin{array}{c}\text { 109 data (30\%) } \\
\text { 14 Sept -31 Dec 2011 }\end{array}$ & $\begin{array}{c}\text { 256 data (70\%) } \\
\text { 1 Jan-29 March 2011 }\end{array}$ & $\begin{array}{c}\text { 14 Sept -31 Dec 2011 and } \\
\text { 1 Jan-29 March 2011 }\end{array}$ \\
\hline
\end{tabular}

Referring to Table 5 above, the next step is to implement the ANFIS Model scheme 1 and scheme 2 based on the composition of the input training data, testing data and simulation data presented as shown in Figure 2 below.

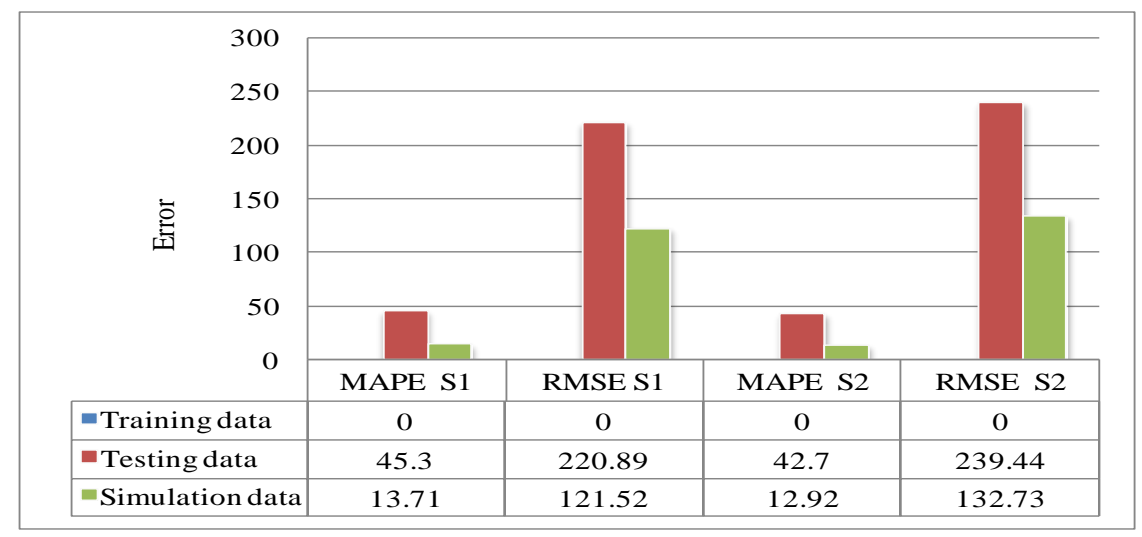

Source: MATLAB program running result

Figure 2 Description of the model ANFIS validate results on the observation value for Scheme 3

Still sourced from Figure 2 above, the simulation results obtained for the application of the ANFIS model without the cross validation method (scheme 1) and with the cross validation method (scheme 2) were tested using MAPE test values with an average error rate of $13.71 \%$ and $12.92 \%$ which have accuracy accuracy of $86.39 \%$ and $87.08 \%$, respectively. Furthermore, the prediction of the Kotopanjang hydro electric reservoir is predicted to be carried out in 2012, with the complete results presented in Figure 3 below

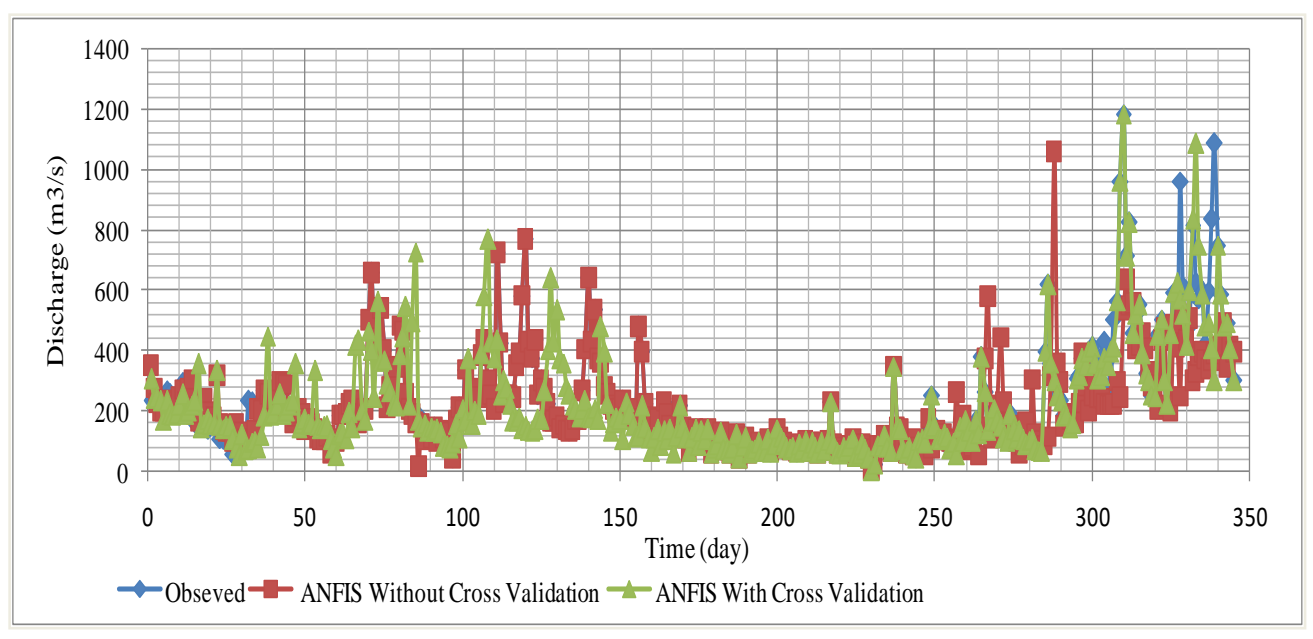

Source: MATLAB program running result

Figure 3 Description of the model ANFIS without and with cross validation inflow prediction for one annual ahead $\left(\mathrm{Q}_{\mathrm{t}+1}\right)$ results on the observation value 
Development of the Inflow Prediction Model on Tropical Reservoir Using Adaptive Neuro Fuzzy Inference System

Referring Figure 3 above, the results of the research proved the use of the model ANFIS algorithm developed a hybrid system between fuzzy logic and artificial neural network as branch of softcomputing that have advantages on recognized pattern data resulted in high prediction accuracy of inflow in Kotopanjang hydro electric reservoir Kampar Regency for one annual ahead $\left(\mathrm{Q}_{\mathrm{t}+1}\right)$ has a degree of very strong relationship with the value of coefficient of correlation (R) of 0.94 and value MAPE of $12.86 \%$ with the classification of relationship is very strong.

\section{CONCLUSION}

Based on the analysis and discussions above, then the following conclusions can be drawn for application of ANFIS model with data input using cross validation method for the need of practice inflow of Kotopanjang hydro electrical reservoir proved to have an average value of the predicted result of smaller errors compared with the ANFIS model for data input without using the cross validation method by a statistical parameter test value a MAPE respectively with a value of $12.86 \%$ and $19.46 \%$ and supported of a correlation coefficient (R) value of 0.94 and 0.90 with a very strong correlation classification, so that the model ANFIS can be used as needs prediction to monitoring fluctuations dynamics of inflow, especially the necessity to maintain the importance of information on sufficient in this reservoir everyday so that the Kotopanjang hydro electric power plant can continue to operate.

\section{ACKNOWLEDGEMENTS}

The author thanked the PT. PLN (Persero) KIT Sumbagut Sektor, KIT Pekanbaru, Riau Province that has granted the use of inflow data on Kotopanjang hydro electric reservoir and Muhammad Idraq Ibnuts Tsauri, ST for the help of statistic analysis and operation of MATLAB 7.0 Toolbox program to support this research.

\section{REFERENCES}

[1] Akbari, D. The role of rainfall against decreased discharge reservoir of Kotopanjanghydro electric power plant reservoir PLTA [online]. Department of Meteorologist Faculty of Earth Sciences and Technology: Institut Teknologi Bandung (ITB) Bandung, 2012.

[2] Bardossy, A., Disse, M. Fuzzy rule based models for infiltration, Water Resources Research, Vol. 29, No 2, 1993, pp. 373-382

[3] Bardossy, A., Duckstein, L. Analysis of karstic aquifer management problem by fuzzy composite programming, Water Resources. Bulletin, Vol. 28, No 1, 1992, pp. 63-73.

[4] Bisht, D. C. S, Raju, M. M, Joshi, M. C. Simulation of water table elevation fluctuation using fuzzy-logic and ANFIS, Computer Modelling and New Technologies, vol. 13, no.2, 2009, pp. 16-23.

[5] Bodri, L., Čermák, V. Prediction of extreme precipitation using a neural network : Application to summer flood occurrence in Moravia, Advances in Engineering Software, 31(5), 2000, pp. 311-321. https://doi.org/10.1016/ S0965-0

[6] Box, G. E. P., Jenkins, G. M. Time Series Analysis Forecasting and Control. Holden Day, San Francisco, 1976.

[7] Campolo, M., Soldati, A., Andreussi, P. Artificial neural network approach to flood forecasting in the River Arno. Hydrological Sciences Journal. 48(3), 2003, pp. 381-398.

[8] Chang, L. C., Chang, F. J. Intelligent control for modeling of real-time reservoir operation. Hydrology Processes 15, 2001, pp. 1621-1634. 
[9] Chang, Y. T, Chang, L. C., Chang, F. J. Intelligent control for modeling of real-time reservoir operation, Part II: Artificial neural network with operating rule curves. Hydrology Processes 19, 2005, pp.1431-1444.

[10] Chang, F. J., Chen, Y. C. A counter propagation fuzzy-neural network modeling approach to real time streamflow prediction. Journal of Hydrology. 245, 2001, pp.153-164.

[11] Coppola, Duckstein, L., Dvis, D. Fuzzy rule based methodology for estimating monthly ground water recharge in a temperate watershed, Journal of Hydrologic Engineering, Vol. 7, No 4, 2000, pp. 326-335.

[12] De Farias, C. A. S., Alves, L. M., Santos, C. A. G., Suzuki, K. An ANN based approach to modeling sediment yield : A case study semi arid area of Brazil: Proceding of the ICCE Symposium Held at Warsaw Poland in Life Science -SGGW Poland, 14 - 18 June 2010 IAHS Publish 557, 2010.

[13] Department of Housing and Regional Infrastructure. River flow discharge forecasting, Research Centre and Water Resources Development, Research and Development of Agency, Department of Housing and Regional Infrastructure, Ministry of Housing and Regional Infrastructure Republic of Indonesia, 2003.

[14] Firat, M. Artificial intelligence techniques for river flow forecasting in the Seyhan river catchment, Turkey, Hydrology and Earth System Disaster 4, 2007, pp.1369-1406.

[15] Firat, M., Gungor, M. River flow estimation using adaptive neuro fuzzy inference system, Journal of Mathematic and Computer in Simulation 75, 2007, pp. 87-98

[16] Fontane, D. G., Gates, T. K., Moncada, E. Planning reservoir operations with imprecise objectives, Journal of Water Resources Planning and Management, Vol.123, No 3, 1997, pp. 154-168.

[17] Giustolisi, O., Laucelli, D. Improving generalization of artificial neural networks in rainfall-runoff modeling. Hydrological Sciencses Journal. 50(3), 2005, pp. 439-457.

[18] Giustolisi, O., Simeone, V. Optimal design of artificial neural networks by a multiobjective strategy: groundwater level predictions. Hydrological Sciences Journal. 51(3), 2006, pp. 502-523.

[19] Hasebe, M., Nagayama, Y. Reservoir operation using the neural network and fuzzy systems for dam control and operation support. Advance Engineering Software 33, 2002, pp. 245-260.

[20] Hu, T. S., Lam, K. C., Thomas Ng, S. A modified neural network for improving river flow prediction. Hydrological Sciences Journal. 50(2), 2005, pp. 299-318.

[21] Ilyas, M. A. Prediction of sedimentation rate in the Kotopanjang hydropower reservoir plan in Riau, Annual Scientific Meeting (PIT) XII, Indonesian Hydraulic Engineering Association (HATHI), Surabaya, 1995, pp. 207-216.

[22] Jang, J. S. R. ANFIS: adaptive network-based fuzzy inference system. IEEE Transaction System, Man and Cybernetics 23(3), pp. 665-685, 1993.

[23] Jang, J. S. R., Sun, C. T., Mizutani, E. Neuro-fuzzy and Softcomputing: A Computational Approach to Learning and Machine Intelligence. Prentice Hall, Englewood Cliffs, New Jersey, USA, 1996.

[24] Kim, T., Choi, G.,Heo, J. H. Inflow forecasting for real time reservoir operation using artificial neural network : World Environmental and Water Resources Conggres: Great Rivers ASCE, 2009, pp. 4947-4955.

[25] Lin, J. Y., Cheng, C. T., Sun, Y. G., Chau, K. Long term prediction of discharges in Manwan Hydropower using adaptive-network-based fuzzy inference systems models. Journal of Lecture Notes in Computer Science. 3612, 2005, pp. 1152-1161. 
Development of the Inflow Prediction Model on Tropical Reservoir Using Adaptive Neuro Fuzzy Inference System

[26] Luk, K. C., Ball, J. E., Sharma, A. An application of artificial neural networks for rainfall forecasting. Mathematic Computing Modeling 33, 2001, pp. 683-693.

[27] Kisi, O. Riverflow prediction using artificial neural network. Journal of Hydrologic Engineering .9(1), 2004, pp. 60-63.

[28] Kim, G., Barros, A. P. Quantitative flood forecasting using multisensor data and neural networks. Journal of Hydrology 246 (1-4), 2001, pp. 45-62.

https://doi.org/10.1016/S0022-1694(01)00353-5

[29] Lohani, A. K., Goel, N. K., Bhatia, K .K. S., Takagi-Sugeno fuzzy inference system for modelling stage-discharge relationship, Journal of Hydrology, Vol. 331, 2006, pp. 146160.

[30] Magar, R.B. 2011. Intermittent reservoir daily inflow prediction using lumped and distributed data multi-linear regression model. Journal of Earth System Science. 120(6), 2011, pp. 1067-1084.

[31] Nayak, P. C., Sudheer, K. P., Rangan, D. M., Ramasastri, K. Fuzzy computing based rainfall-runoff model for real time flood forecasting. Hydrology Processes 17, 2004a, pp. 3749-3762.

[32] Nayak, P. C., Sudheer, K. P., Rangan, D. M., Ramasastri, K. S.A neuro-fuzzy computing technique for modeling hydrological time series. Journal of Hydrology 291, 2004b, pp. $52-66$.

[33] Ouenes, A. Practical application of fuzzy logic and neural networks to fractured reservoir characterization. Computer Geosciene 26, 2000, pp. 953-962

[34] Özelkan, E. C., Duckstein, L. Fuzzy conceptual rainfall-runoff models. Journal of Hydrology. 253, 2004, pp. 44-68.

[35] Panigrahi, D. P., Mujumdar, P. P. Reservoir operation modelling with fuzzy logic, Water Resources Management, Vol. 123, No 3, 2000, pp. 154-168.

[36] Ponnambalan, K., Karry, F., and Musavi, S.J. Minimizing variance of reservoir systems benefits using softcomputing tools. Fuzzy Sets System 139, 2003, pp. 451-461.

[37] Rantala, J., Koivisto, H. Optimised subtractive clustering for neuro-fuzzy models. In: Third WSES (World Scientific and Engineering Society) International Conference on Fuzzy Sets and Fuzzy Systems (Interlaken, Switzerland), 2002.

[38] Refsgaard, J. C. Towards a Formal approach to calibration and validation of models using spatial data, in R. Grayson and G. Blöschl. Spatial Patterns in Catchment Hydrology: Observations and Modelling, Britain: Cambridge University Press, 2000, pp. 329 - 354.

[39] Rowiński, P. M., Piotrowski, A., Napiórkowski, J. J. Are artificial neural network techniques relevant for the estimation of longitudinal dispersion coefficient in rivers ? Hydrological Sciences Journal 50(1), 2005, pp.175-187.

[40] Sajikumar, N., Thandaveswara, B. S. (1999). A non-linear rainfall-runoff model using an artificial neural network. Journal of Hydrology, 216(1-2), 32-55. https://doi.org/10.1016/S0022-1694(98)00273-X

[41] Salas, J. D., Shin, H. S. Uncertainty analysis of reservoir sedimentation. Journal of Hydraulic Engineering 125(4), 1999, pp.339-350.

[42] Şişman-Yilmaz, N. A., Alpaslan, F. N., Jain, L. ANFIS_unfolded_in_time for multivariate time series forecasting. Neurocomputing 61, 2004, pp. 139-168

[43] Sudjarwadi. Difficulty prediction of reservoir sedimentation rates based on echo sounding data, Annual Scientific Meeting (PIT) XII, Indonesian Hydraulic Engineering Association (HATHI),Surabaya, 1995, pp. 199-206. 
[44] Suprayogi, I. Model of Salt Intrusion Forecasting in Estuary Using Softcomputing, Dissertation, Surabaya : Management and Water Resource Engineering, Department of Civil Engineering, Faculty of Civil Engineering, Environmental and Earthquake, Sepuluh Nopember Institute of Technology (ITS), 2009.

[45] Suprayogi, I., Sandhyavitri, A., Nurdin, Joleha, Wawan, Azmeri. Groundwater level forecasting model in tropical peat land using artificial neural network. International Journal of Civil Engineering and Technology. 11(2), 2020, pp.68-78.

[46] Sy, N. L. Modelling the infiltration process with a multi-layer perceptron artificial neural network. Hydrological Sciences Journal. 51(1), pp. 3-20.

[47] Verniuwe, H., Georgiva, O., de Baets, B., Pauwels, V. R. N., Verhoest, N. E. C., de Trouch, F. P. Comparison of data driven Takagi-Sugeno models of rainfall-discharge dynamics. Journal of Hydrology 302, 2005, pp.173-186.

[48] Wilby, R. L., Abrahart, R. J., Dawson, C. W. Detection of conceptual model rainfallrunoff processes inside an artificial neural network. Hydrological Sciences Journal .48(2), 2003, pp. 163-181.

[49] Zadeh, L.A. Fuzzy sets, Information and Control, Vol.8, No 3, 1965, pp. 338-353. 